(C) 2012

HAILEY L. MILLS

ALL RIGHTS RESERVED 


\title{
AVATAR CREATION: THE SOCIAL CONSTRUCTION OF "BEAUTY" IN SECOND LIFE
}

\author{
A Thesis \\ Presented to \\ The Graduate Faculty of The University of Akron
}

\author{
In Partial Fulfillment \\ of the Requirements for the Degree \\ Master of Arts
}

Hailey L. Mills

December, 2012 


\title{
AVATAR CREATION: THE SOCIAL CONSTRUCTION OF "BEAUTY" IN SECOND LIFE
}

\author{
Hailey L. Mills
}

Thesis

Approved:

Accepted:

Advisor

School Director

Dr. Tang Tang

Dr. Elizabeth Graham

Committee Member

Dr. Yang Lin

Dean of the College

Dr. Chand K. Midha

Committee Member

Dean of the Graduate School

Dr. Kathleen Clark

Dr. George R. Newkome

Date 


\begin{abstract}
Rooted in the Theory of Social Construction of Reality and informed by media and gender portrayal and virtual communities research, this study examines how beauty is socially constructed in Second Life. Specifically, a content analysis of 360 still images of female avatars was conducted to understand how people construct beauty in a virtual community. Findings suggest that people chose gender stereotypical images even when they have the free choice to create any avatar they desire. Trendy and sex kitten/sensual beauty types were the most-portrayed beauty types. Almost all the female avatars had a perfect body size. And more than $80 \%$ of the avatars coded in this study had light skin. In addition, this study found a significant difference in beauty type among avatars with different amounts of body coverage and a significant difference in beauty type among different types of products. However, no significant difference was found in beauty type between avatars with different skin color nor was there a significant difference in beauty type among avatars with different body sizes. Overall, this study provides valuable insights in understanding how beauty is socially constructed in the virtual world and advances the theory of social construction of reality in today's dynamic environment.
\end{abstract}

Keywords: Theory of Social Construction of Reality; media and gender portrayal; Second Life; virtual worlds; female beauty 


\section{ACKNOWLEDGEMENTS}

I would like to thank Dr. Tang Tang for the unconditional support, countless hours of reviewing my drafts, words of encouragement, and believing in me. I cannot express how thankful I am to have you as my thesis director. Without your compassion, expertise, and loyalty, I would not be where I am today. I would also like to say thank you for giving me candy, cookies, and chips when I visit your office, our conversations about shoes, and for the advice you have given me as I continue on my life journey.

I would like to thank Dr. Kathleen Clark for providing a unique perspective to my thesis. Coming from a quantitative background, your qualitative knowledge put my thesis into new perspective. Your vision and knowledge provided me with the tools I needed to complete my thesis. I would also like to thank you for your patience and being the sounding board I needed. Some days, I just needed to unwind.

I would like to thank Dr. Yang Lin for providing me the skills and tools needed to conduct my statistical tests. Your knowledge of quantitative methods and keen vision proved to be valuable assets as I completed my thesis. I would also like to thank you for the opportunities you have provided me and seeing my potential when others were blind. Words cannot express how thankful I am to know you. 


\section{TABLE OF CONTENTS}

Page

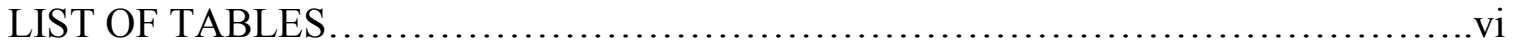

\section{CHAPTER}

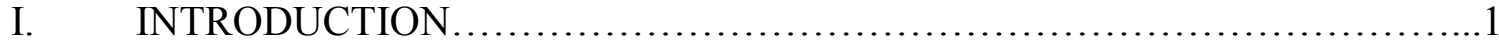

II. LITERATURE REVIEW ..............................................

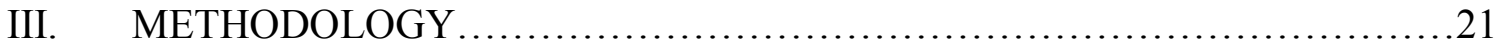

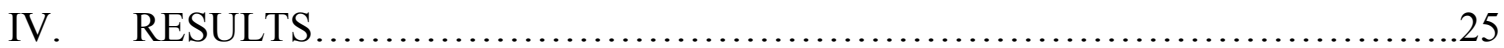

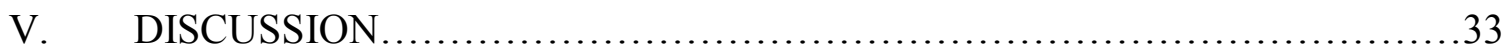

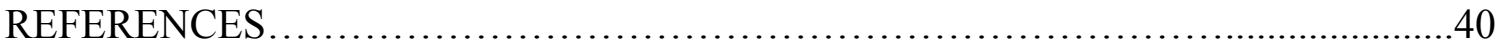

APPENDICES ............................................................................

APPENDIX A. CODING SHEET .................................................48

APPENDIX B. CODING BOOK...........................................50

APPENDIX C. EXAMPLES OF AVATARS ...............................52 


\section{LIST OF TABLES}

Table

Page

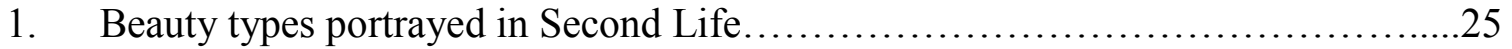

2. Skin color featured in Second Life...........................................

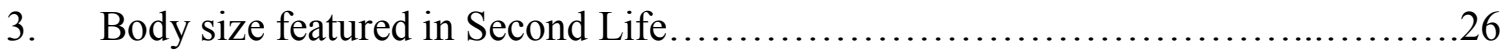

4. Body coverage featured in Second Life.....................................27

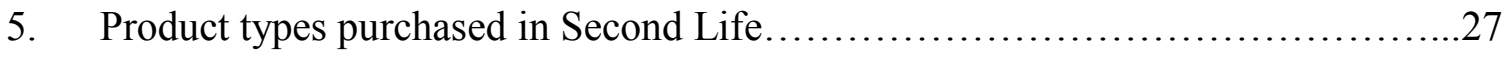

6. Differences in beauty type between avatars with different skin color..............28

7. Differences in beauty type among avatars with different body size..................29

8. Differences in beauty type among avatars with different amount of body

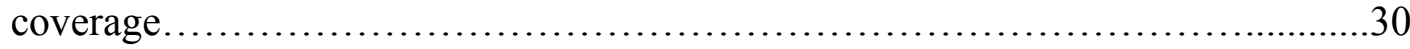

9. Differences in beauty type among different types of products.................... 


\section{CHAPTER I}

\section{INTRODUCTION}

The Internet has substantially changed the way people work, play, think, consume and connect (Chu, Paul, \& Ruel, 2009). In 2011, 272,066,000 people used the Internet (Internet Users \& Population, 2011). Fifty-five percent of Americans use the Internet every day, spending 60 hours every month online. About 70 percent of all Internet users participate in social networking and 15 percent of those users log onto social networking

sites everyday (Smith, 2010). With numbers increasing daily, there is a need to find out to what extent the Internet has changed the conditions of social interaction, and whether or not such changes have altered the ways in which individuals construct the reality of their everyday life (Zhao, 2006).

Within the world of the Internet, the omnipresence of virtual communities has made it an inevitable part of everyone's lives and influenced people's conception of reality. Virtual communities have served as a place where people share interests, develop new social relationships, create fantasies, and/or conduct transactions through Internet based technology. Researchers suggest that these communities have a major impact on 
enhancing Internet users' online experience as they have entered into everyday life (Harrison, 2009; Lin, 2009).

Second Life is one of the most popular virtual communities, with more than one million "residents" today (Huang, 2011). Developed in 2003, by Linden Labs, the purpose of Second Life is to give people the option to live a second life. This threedimensional online environment allows residents to interact, participate in activities, attend events, and do anything else that can be done in the real world (Huang, 2011; Brennen \& dela Cerna, 2010). As people join the Second Life community, the first task they face is to create an avatar to represent who they are. Ideally, they can be whoever they want to be. In practice, research suggests Second Life players try to make their avatars look "pretty" in order to be noticed (Padilla-Miller, 2009). Thus, it is important to understand how people create their avatar in Second Life, particularly how beauty is socially constructed in virtual communities when they have "complete" freedom to do so.

Within scholarship, researchers suggest that media can shape perceptions of image and beauty. According to Berger and Luckmann (1967), "the mass media do not reflect the world in any empirical sense, but instead help construct and maintain it by representing meanings and understandings of reality" (Ibroscheva \& Ramaprasad, 2007, p. 3-4). The media do not invent the standards of image creation. They perpetuate and reinforce what has already been invented.

In addition, researchers found that the media emphasized stereotypes and gender roles. In 2009, Bullen conducted a study on the impact of advertisements and found that 
people view an average of 16,000 advertisements, logos, and announcements pertaining to gender stereotypes daily. These advertisements portrayed women as powerless and generally focused on females' bodies and sex rather than their minds and capabilities. Such images reinforce the stereotypes and send a message that women are to fit into the societal stereotypes in order to belong (Bullen, 2009).

As such, mass media is one of the most powerful and influential sociocultural factors contributing to body dissatisfaction in Western society. Magazines like Seventeen and Glamour were more likely to report "dieting to lose weight because of pictures in magazines" (Pitura, 2010, p. 62). Research examining the effects of media exposure demonstrates that media consumption has a measurable influence on people's perceptions of the real world, and regardless of the accuracy of these perceptions, they are used to guide subsequent attitudes, judgments, and actions. "Gender portrayal has an effect on individuals' real-world gender-based attitudes, beliefs, and behaviors" (Behm-Morawitz \& Mastro, 2009, p. 131).

Numerous studies on gender portrayal in the media and on the Internet confirm that gender inequalities still exist in society. Behm-Morawitz and Mastro (2008) suggest that media impact on individuals' social construction of reality, real-world gender-based attitudes, beliefs, and behaviors. However, few researchers examined beauty portrayal in virtual communities. In addition, among the emerging virtual communities research, little attention has been given to the gender portrayal in Second Life. Thus, this study aims to address the gap by examining how beauty is socially constructed in Second Life. Specifically this study focuses on how female avatars were featured in the Second Life Marketplace. 


\section{CHAPTER II}

\section{LITERATURE REVIEW}

The Theory of the Social Construction of Reality was proposed by Peter Berger and Thomas Luckmann in 1966. Berger and Luckmann (1966) explain the process by which human knowledge about the social world is created, transmitted, preserved, and comes to be taken for granted. Society is best understood in terms of an ongoing dialectical process composed of the three moments of externalization [i.e. institutionalization], objectivation and internalization [i.e. socialization]. "Individuals are both the producers and the products of society and to be members of society means to be a part of this ongoing dialectical process" (Storr, 2010, p. 200).

Social construction of reality (SCR) suggests that meaning is unfixed and that reality is socially constructed during communication $(\mathrm{Wu}, 2006)$. Within this theory, there are two fundamental concepts, reality and knowledge (Berger \& Luckmann, 1966; Brabant, 2010). Reality refers to "a quality appertaining to a phenomenon that we recognize as having a being independent of our own volition (we cannot wish them away)" (Brabant, 2010, p. 222). Knowledge pertains to "the certainty that phenomena are real and that they possess specific characteristics" (Brabant, 2010, p. 223). One person 
may see something and think it is real, while another person possesses different characteristics about what is real (Berger \& Luckmann, 1966; Brabant, 2010).

For Berger and Luckmann, reality and knowledge are relevant not only to the philosopher but to the ordinary person as well. The difference is that the ordinary person lives in a "taken for granted" reality; the philosopher is concerned with its validity or invalidity. For the sociologist, the social relativity of both reality and knowledge is of paramount importance (Berger \& Luckmann, 1966; Brabant, 2011). They wrote:

It is our contention , then, that sociology of knowledge must concern itself with whatever passes for "knowledge" in a society, regardless of the ultimate validity or invalidity (by whatever criteria) of such "knowledge." And insofar as all human "knowledge" is developed, transmitted, and maintained in social situations, the sociology of knowledge must seek to understand the process by which this is done in such a way that a "taken-for-granted" reality congeals for the [ordinary person]. (p. 3; p. 223)

The ultimate questions that are asked when addressing the concepts of reality and knowledge are as follows: "What is real?" and "How is one to know?" (Berger \& Luckmann, 1966, p. 2-3). Berger and Luckmann (1966) argue that people will never fully know what is considered real because they are not forced to think about it. People take for granted the things that go on around them and the decisions that they make every day. It is difficult to know what can be justified as real because what is real to one person is not to another person. For example, "the knowledge and reality of a criminal differs from the knowledge of a criminologist" (Berger \& Luckmann, 1966, p. 3).

The reality of everyday life is difficult to fully understand. Life exists as its own platform. That platform itself is reality. That reality is interpreted by people. The 
interpretations are subjective and they give meaning to people about the world (Berger \& Luckmann, 1966). Ultimately, the world is taken for granted as reality because each person's subjectivity gives him/her personal meaning to his or her life. Each person's subjectivity originates in his or her thoughts and actions and is manipulated by the same thoughts and actions (Berger \& Luckmann, 1966; Luckmann, 1967).

Manipulation occurs through the use of symbols to communicate. Humans use symbols to create different versions of reality and internalize the constructions as fact or truth (Menegatos, 2007). Symbols represent the "structural" trait of the world as a whole. They are interpretative schemes that do not have an isolated meaning. Symbols are arranged in a hierarchy of significance, which gives certain people power over others. The hierarchal arrangement is the structural trait of the real world (Luckmann, 1967).

Among the multiple realities there is one that presents itself as the reality par excellence. Berger and Luckmann (1966) describe the reality of everyday life:

Reality's privileged position entitles it to the designation of paramount reality. It is difficult to ignore or weaken this presence as it is already objectified in the mind. The world consists of things to constantly reinforce a mindset from can openers to sports cars, which are designated in the technical vocabulary of society. The objectified reality is different for one person to another because life presents itself in an intersubjective world, a world that is shared by many. One person will be alone when dreaming, but the world of everyday life is as real for each person as they will correspond between each other's meanings about the world. (p. 21)

The reality of everyday life is taken for granted as reality. It does not require additional verification over and beyond its simple presence. It is simply there and it is just real. People perform certain functions and make certain decisions on a daily basis 
because it is part of reality. "There is no thought process behind a daily routine" (Berger \& Luckmann, 1966, p. 23). Everyday life is something that is shared by everyone. People share life through face-to-face interactions. In a face-to-face situation, each person comes together and each person will stick out vividly in someone else's mind as long as $\mathrm{s} / \mathrm{he}$ remains a part of the situation. As a result, there is a continuous interchange of expressivity from smiling to frowning (Armstrong \& Ferguson, 2010). Sometimes, people can misinterpret the way others react to something that is said. For example, a person could be perceived as smiling when really the person is smirking. Regardless of how one perceives anything that is seen or heard, the other person is fully real because of the physical presence at the time (Berger \& Luckmann, 1966).

Human expressivity manifests itself into the world as people communicate with each other. For instance, a subjective attitude of enjoyment is directly expressed in the face-to-face situation by a variety of bodily indices-nodding of the head, smiling, and leaning toward someone when listening (Armstrong \& Ferguson, 2010). Another instance is the human production of signs. A sign is unique because of its explicit intention to serve as an index of subjective meanings (Berger \& Luckmann, 1966). For example, a weapon may have originally been produced for the purpose of hunting animals, but may then become a sign for aggressiveness and violence in general. There are certain objectifications specifically intended to serve as signs. For example, instead of throwing a 
knife at someone to indicate death, an adversary could paint a black X-mark on a door to indicate the same meaning (Berger \& Luckmann, 1966).

Lipschultz and Hilt (1999) state that Berger and Luckmann's Theory of Social Construction of Reality began with the philosophical view that all symbolic universes and all legitimations are human products; their existence has its base in the lives of concrete individuals, and has no empirical status apart from these lives. Berger and Luckmann (1966) make two assumptions regarding human nature: (1) human beings are inherently unstable and thus, have a biological need to create order or meaning out of the world around them, and (2) human beings are inherently social animals, and it is through social interaction that they create stability and/or societal norms and values (Lipschultz \& Hilt, 1999). Social construction emphasizes the importance of language because it allows people to label, organize, and explain the world they live in. Through the coarse of socialization, the meanings behind words and things are internalized, affecting identities as individuals and societies, and calms the inherent fear of social instability (Menegatos, 2007).

Siu (2006) states that the Berger and Luckmann's (1966) Theory of Social Construction of Reality is constructed on four basic assumptions: (1) reality does not present itself objectively to the viewer. It is understood through human experience; (2) categories of language are determined by social interactions in force of a particular time; (3) how reality is defined is determined by the "conventions of communication"; and (4) communication behavior constitutes the social construction of reality. Meaning can never 
be fixed. People have conceptual maps that organize and assign meaning to events (Siu, 2006).

The Theory of Social Construction of Reality contends that mass media do not reflect the world in any empirical sense, but instead help construct and maintain it by representing meanings and understandings of reality (Berger \& Luckmann, 1966). The media are part of larger social processes that construct and encourage some meanings (those of dominant social groups) over others (social subordinate groups) and they do so via discourse (language that is infused with particular meanings and not others) (Ibroscheva, Ramapasad, 2008).

A number of scholars have used Berger and Luckmann's Theory of Social Construction of Reality as the theoretical frame to guide research in the field of communication (Brabant, 2010). Ibroscheva and Ramaprasad (2007) state that social construction of reality affects the way people stereotype. People stereotype because of media exposure, nature of the media source, media content, and the effect of the media. Rodkin (1993) found that the white race was acknowledged more often in the virtual world. Social constructions had an impact on psychological reality in relation to race. Anathaswamy (2007) also suggests that people no longer construct their reality only in real life. Lives are now constructed on the Internet because people can be whoever they want to be in a virtual community.

In the online world, people create identity by designing images of themselves, signatures of e-mails, and any other way to use symbols that represent who they are 
online (Zheng, Young, Wagner, \& Brewer, 2009). When people post information on social media sites, they offer a representation of the self. For example, on Facebook, users often select photographs to be shown based on how others will respond to them. Selecting images to be shown is a symbolic act of communication. When pictures are selected, the self emerges through perception, meaning, and the social construction of reality (Ellis, 2010).

The social construction of reality impacts the way people see the world. It suggests reality is socially constructed based on what people already know. Ideas that are presented overtime become one's reality. As the reality develops, the reality becomes fact in the human mind. Overtime, the reality created in the mind is reified, as media outlets continue to reinforce it. This presents an interesting issue. Do people create their own reality or do media construct one's reality? As reality is constructed, do people believe in the reality because they truly believe in it or because society keeps reinforcing it?

Biological determination assumes that people are born as a man or a woman (Damme, 2010). However, researchers contend that biology does not determine gender. Gender is socially constructed, which means one is not born, but rather becomes, a man or a woman (Morris, 2006; $\mathrm{VoCiCi}, 2008)$. The construction of gender begins early in life. When girls are born, they have pink blankets in the hospital (Morris, 2006). As children, girls are socialized to play with dolls, be cooperative, and to experiment with clothes and makeup. As they become older and turn into women, the standards they learned as girls will follow them into their professional and personal lives (VoCiCi, 
2008). Women are shown as beautiful humans noted for their body shape and other physical features. A female's sexuality can shape the opinion of people within the boundaries of gender portrayal (Ilbuga, 2010).

The beauty myth suggests that there is a stereotypical beauty standard. This standard is represented by Eurocentric features such as white skin, blond hair, blue eyes, as well as youth, and low body weight (Conrad, Dixon, \& Zhang, 2009). Researchers suggest individuals with light skin were used more often in the media over those with dark skin (Conrad, Dixon, \& Zhang, 2009). Mbure (2009) conducted a study of female model representation in six African-origin magazines. They found that they majority of models had light skin and long hair. Lin and Yeh (2009) also demonstrated that the majority of women used in magazine advertisements stood, they were partially nude, and all of the women who were examined in the study had light colored skin.

In addition, many studies found that women were more likely to be shown as sex objects or "decoration" in the media. In general, women took on less serious roles (e.g., passive, housewife, etc.) in advertisements. When female models are depicted in professional roles in advertisements, they were not perceived to be as serious about completing job tasks as men (Morris, 2006). On television, females are underrepresented compared to their male counterparts. Male characters tended to work outside of the home more often, had a wider range of jobs, and had higher status and higher paying occupation than did female characters. Female characters remain younger than male characters (Emons, Wester, \& Scheepers, 2010). In addition, female characters were 
more likely to have fit bodies than their male counterparts, and were more attractive than male characters. They also wore skimpy clothing and were more likely to be the object of another's gaze than males (Signorielle \& McLeod, 1994).

Researchers also suggest that regardless of how a woman wants to be perceived, one of the most powerful weapons any woman can own is beauty (see Joseph, 1982; Patzer, 1985). Beauty has a strong, pervasive impact on people's lives. A beautiful woman can gain power, social influence, and perceived intelligence (Patzer, 1985). Joseph (1982) found that attractive people were perceived as more credible than unattractive people because of the socialization of the media. Attractive females were seen as having more positive qualities and possessing more desirable traits such as strength, sexual warmth, sensitivity, kindness, and modesty. Additionally, attractive females tended to lead happier and more fulfilling professional and personal lives than did unattractive ones (Benoy, 2009).

Media are instrumental in shaping and framing standards of beauty. They control what people see and how they perceive beauty. Beauty portrayal is not seen as a singular concept. Rather, there are many types of beauty that exist within the media. Researchers summarized eight types of beauty: classic (perfect physical, especially facial features), cute (child-like physical features and/or attire), sex kitten (sexual looks, overt and youthful), sensual (sexual looks), girl next door (natural, unmade-up appearance and simple attire), exotic (non-Causasian), feminine (a soft and/or romantic look), and trendy 
(an off-beat look, perhaps flawed or asymmetrical, in contrast of a classic beauty type) (Solomon, Ashmore, \& Longo, 1992).

Englis, Solomon, and Ashmore (1994) examined the different beauty ideals and how these ideals were distributed across different media platforms. They found that beauty was not evenly distributed. The beauty type depended on the type of magazine. Specifically, fashion magazines used the exotic beauty type most often, while youth magazines focused on classic and girl next door beauty types. Goodman, Morris, and Sutherland (2008) conducted a study on women's emotional responses to different beauty types presented in magazine advertisements. They found that women had the most positive emotional response when they saw a classic beauty type. Women had the most negative emotional response to sensual/exotic beauty type.

Gender remains a widely studied area among communication scholars. This is largely due to the fact that the standard of beauty is constantly reinforced by the media. The media showcase that the majority of women have traditional, European physical traits. Overtime, people believe what they see and continue to reinforce that the media standard for beauty are what is considered attractive. Regardless of how a female wants to be perceived, media perpetuated images are constantly reinforcing societal expectations of what it means to be an attractive female.

A virtual community is defined as a community founded intentionally by people who share a set of similar interests, often revolving around certain texts or tropes imported from non-computer mediated communication venues (McQuail, 2010). It is a 
computer generated version of a real-life setting that can be experienced in a variety of formats (e.g., individualized computer video game, 3D game, or as a collaborative learning environment) (O’Brien \& Levy, 2008). They can be formed by any number of individuals who have Internet access. People join virtual communities because of interactions, a common purpose, and a sense of identity and belonging. Within these communities, there are rites, rituals, and forms of expression unique to each community (McQuail, 2010).

Defining characteristics of virtual communities are interactivity, threedimensionality, and real-time feedback. Users feel a sense of presence when they are in a virtual community. This means that users feel they are inside of the computer world rather than just looking at a video game display (O'Brien \& Levy, 2008). People are able to communicate amongst those who would never be able to communicate in person and it is a revolutionary way to explore worlds that are too far away, too small, too experimental, or too dangerous for ordinary access (Harrison, 2009; O’Brien \& Levy, 2008). While real life communities are often hard to enter, virtual communities are more open and accessible (McQuail, 2010).

Barker (2008) suggests, within a virtual community, individuals create a sense of identity called the virtual self. The virtual self involves the interface and interaction between an individual and the external environment, in order to increase his or her personae. The virtual self is created to cope with chaotic and constantly changing patterns of knowledge-driven choices, decisions, impact assessments and novel or iterative next 
steps, which define much of personal capital (Jin, 2012). Furthermore, the virtual self capitalizes on diversity. The creation of self in cyberspace is not incidental but intentional. It is positive and influential to attract attention, create own identities, and strengthen commitment and involvement in online relationships (Barker, 2008).

In 2003, Linden Labs, a San Francisco based corporation, launched the virtual game, Second Life. Second life (SL) is defined as an online society within a threedimensional virtual world entirely built and owned by its residents, where they can explore, build, socialize and participate in their own economy (Diehl \& Prins, 2008). This virtual world began with only 16 servers and approximately 1,000 users. In 2008, there were 250 employees and over 14 million residents (Atkinson, 2008a; Atkinson, 2008b). Today, roughly one million residents, basic or premium, have logged into SL at least once a month. The average in-world concurrency is 50:104. This means that whenever someone logs into SL, there are around 50,000 residents interacting with each other (Huang, 2011).

This game is unique because it has no predetermined player goals, leading many to conclude that Second Life (SL) is not a game, but rather a virtual environment where people from all over the world navigate and create the virtual environment (Diehl \& Prins, 2008). Second Life's technology allows residents to build anything imaginableclothing, vehicles, furniture, and buildings (Huang, 2011). Users can explore various lands from seaside towns to educational institutions. Residents also meet and speak with 
each other and buy a wide variety of virtual products, ranging from shoes, cars and houses (Atkinson, 2008a).

According to the Second Life Marketplace (2012), the currency in SL is the Linden Dollar, which can either be obtained by exchanging U.S. dollars via the SL exchange or by searching for a job that pays for his or her living in Second Life. Linden dollars can be re-exchanged into U.S. dollars, making it possible to earn real life money by selling virtual products and services within SL. In 2012, the Second Life Marketplace (2012) says one U.S. dollar was equivalent to 247 linden dollars. This "two-way exchange possibility for Linden dollars has evolved toward a virtual economy" (Kaplan \& Haenlein, 2009, p. 93).

If Second Life residents need to go shopping, they shop at the Second Life Marketplace. The Marketplace is the universal location for all residents to purchase and sell items (Second Life Marketplace, 2012). Shopping on the Marketplace can be compared to shopping on any online store. The only difference is that residents purchase items for their Second Life account instead of for themselves (Harambam, Aupers, \& Houtman, 2011). In the Marketplace, residents can choose to purchase items for their virtual home, pets, vehicles, physical appearance, and much more. Like normal online shopping, residents shopping on the Marketplace can narrow their search based on category, maturity level, key words, number of items per page, and other criterion (e.g., best-selling, most expensive, etc.) (Second Life Marketplace, 2012).

Everyone interacts, in Second Life, via avatars. The term avatar originated from avatarah, a Sanskrit word meaning incarnation, which refers to the visible, embodied 
forms with which Hindu gods represented themselves when they interacted with human being (Bélisle \& Bodur, 2010; Lee \& Park, 2009). Bélisle and Bodur (2010) suggest that avatar refers to the "manifestation of a deity, notably Vishnu, in human, superhuman or animal form" (p. 743). "Just as the avatarah was used by Hindu gods for embodiment, avatars in the current digital culture are used by people for self-representation in various computer-mediated environments" (Lee \& Park, 2010, p. 5). As computer-mediated environments become a part of everyday life, avatars are defined as graphical or visual representations of people in networked online environments (Lee \& Park, 2010). Lee and Park (2010) suggest that three-dimensional (3-D) avatars whose behaviors can be controlled by the users are not seen only in multiplayer online games but also in 3-D immersive virtual worlds. Bélisle and Bodur (2010) suggest that avatars are the only means by which people in virtual worlds present themselves to others and create their identity.

Neal Stephenson's novel-Snow Crash was the first science fiction story to feature both the concept of virtual worlds and avatars. Originally published in 1992, Snow Crash introduces the concept of the Metaverse, which is "a virtual reality world envisioned as a large cyber planet" (Lee \& Park, 2010, p. 6). It consists of visual representations mapped onto virtual reality goggles and audio cues transmitted into earphones (Lee \& Park, 2010) Lee and Park (2010) state that in the Metaverse, avatars are highly customizable, as describe below:

Your avatar can look any way you want it to, up to the limitations of your equipment. If you're ugly, you can make your avatar beautiful. If you've just gotten out of bed, your avatar can still be wearing beautiful clothes and professionally applied makeup. (p. 6) 
Just as avatars in Snow Crash are highly customizable, the real-world 3-D avatars in existing virtual worlds allow people to customize their bodies that complement social interaction with other users in the networked setting. In Second Life, avatars display physical features associated with certain social categories (e.g., gender, race/ethnicity, age), walk around the virtual space, and communicate with other users verbally and nonverbally (Lee \& Park, 2010).

In Second Life (SL), residents have full ownership of their virtual creations (Huang, 2011). The virtual world offers limitless possibilities for creating an avatar. Since there are no boundaries, anyone can be who they want to be. Some SL users even refigure gender, and choose to create opposing gender avatars (Brookey \& Cannon, 2009). As people create avatars, they can create an avatar that looks exactly like themselves or nothing like themselves (Padilla-Miller, 2009). Many times, people choose to create an avatar based on unrealistic standards of beauty that are unattainable in real life (i.e., hair, structured face, and a body that looks like a 1950's Barbie doll). Thus, researchers suggest that the avatars reflect signs of the creator's self, deliberately or nonconsciously (Belisle \&Bodur, 2010).

Second Life is appealing to people because people can choose to have the look they desire. Anyone can change the way they look with a few clicks of the mouse (Ananthaswamy, 2007). Ayiter (2010) found that just as people choose their selfrepresentations in virtual environments, their self- representations shaped their behaviors in turn. These changes happen not over hours or weeks, but within minutes. In the real world, people are used to the disappointments that come from the inability to achieve a certain look (Padilla-Miller, 2009). When people enter the virtual world, they seek to 
create an avatar that is with a perfect body shape, fake-looking, and enhance the avatar to their satisfaction. Essentially, people want to experience what it is like to look a certain way, even if the experience is virtualized (Hall, 2008).

Rak (2009) found that appearance is even more important in Second Life than in real life because the creation of an Avatar was the primary factor that identified a person. Padilla-Miller (2009) suggests that creating an Avatar was based on three layers. The first layer was avatar construction. The second layer was the reason for choosing the creation of an avatar. Avatars are created to either represent who a woman is or who a woman wishes to look like in real life. The third layer pertains to a woman's actual body image. Female SL players either looked like their avatars in real life or looked completely opposite of their avatars (Padilla-Miller, 2009).

Not too long ago, people could only change certain physical characteristics about themselves. Now, they have the option to go online and change any physical characteristic they desire. As people become aware of this, the number of Second Life users continues to increase. Overtime, the constant exposure to the avatars lets people know what their avatars should look like. Second Life constructs images in the human mind and people believe that the constructed images are valid and realistic. The created symbols affect people's perception of what it means for a woman to be beautiful in Second Life.

Literature on the Theory of the Social Construction of Reality focuses on symbol creation, but little attention has been given to the creation of symbols in the virtual world. In addition, few researchers have studied gender portrayal in Second Life. As the game 
increases in popularity, it is important to understand how people create their avatars. More importantly, it is critical to examine if the same stereotypes exist when people have total control of their avatars' appearance. Researchers suggest that constant exposure to these stereotypes can cause one to become angered, have high levels of anxiety, and possibly depression (Robinson, Callister, Clark, \& Phillips, 2009). Thus, there is clearly a need to examine the issue of socialized beauty construction in Second Life. Thus, this study aims to examine how beauty is socially constructed in Second Life. This focus serves as a guide for the following research questions:

RQ1: What female avatar items are purchased most often for creating an avatar in Second Life?

RQ2a: Is there a significant difference in beauty type between avatars with different skin color?

$R Q 2 b$ : Is there a significant difference in beauty type among avatars with different body size?

RQ2c: Is there a significant difference in beauty type among avatars with different amount of coverage?

RQ2d: Is there a significant difference in beauty type among different types of products? 


\section{CHAPTER III}

\section{METHODOLOGY}

This study conducted a content analysis to examine how beauty is socially constructed in Second Life. Wrench, Thomas-Maddox, Richmond, and McCroskey (2008) suggest a content analysis can "summarize visual images, characterizations, and other messages that are sent" (p. 244). Thus, a content analysis of 360 still images of female avatars in Second Life was conducted. A total of 360 still images of full-bodied, female avatars were analyzed. The unit of analysis for this study was full-bodied, still images of female avatars. Only female avatars were selected because this study is focused on female beauty portrayal.

Data for this study were collected via the Second Life Marketplace, which is the universal location for all Second Life residents to purchase products for creating an avatar (Huang, 2011). Three categories were selected for coding: (1) avatar accessories; (2) avatar apparel; and (3) avatar appearance. These categories were selected because residents can choose to purchase items for creating a female avatar in these categories. The best-selling items were selected for coding, because these are the items people purchased most often. Also, a general maturity level was selected for coding. This maturity level was selected for coding because it produced the most number of results. 
Purposive sampling was selected as the method for obtaining the images. Overall, the first 120 images of full-bodied, still, female avatars from each of the three categories (accessories, apparel, and appearance) were selected for coding.

This study coded the following variables: beauty type, skin color, body size, coverage, and product type. To code beauty type, Solomon, Ashmore, and Longo's (1992) study on multiple beauty types was utilized as a reference. Four beauty types were coded in this study accordingly, including: classic, cute/girl next door, sex kitten/sensual, or trendy. Classic beauty was defined as having a classic or elegant look. A classic beauty type displayed symmetrical physical features, had a soft, romantic look, and wore classy, formal attire. Cute/girl next door beauty was defined as having youthful physical features and could look like fresh-faced-teenagers. These avatars looked outdoorsy, athletic, and wore casual attire. Sex kitten beauty was defined as wearing sexy attire that is revealing or very tight. These avatars could be dressed in normal clothes, but posed in an unnatural, uncomfortable way. Trendy beauty was defined as wearing faddish clothes, displayed oversized accessories, and the hair was tousled. Theses avatars look like they have imperfections.

In addition, skin color was coded as light or dark skin. Light skin was defined as porcelain, light ivory, sun beige, warm beige, and nude. Dark skin was defined as light cocoa, caramel, honey beige, cocoa, tawny, tan, espresso, and nut brown (Covergirl \& Olay, 2012; Dream Nude Airfoam, 2012; True Match Super, 2012). Body size was Categorized as thin, average, and overweight. If an avatar had no curves, the avatar was coded "thin." If an avatar had excess body fat, stomach rolls, and enlarged thighs, the avatar was coded as "overweight." If the avatar was not considered thin or overweight, it 
was coded as “average." Coverage was coded as covered a lot, covered modestly, and covered very little. A lot of coverage was defined as when an avatar showed none to less than half of the total body skin, looked conservative, and had no inappropriate body parts exposed. Moderate coverage was defined as when an avatar showed about half of the total body skin, wore a bra and pants set at the same time and it did not look like she was naked. Little coverage was coded when an avatar exposed more than half of the total body skin, wore skimpy lingerie or a skimpy outfit, and had private parts fall out of the clothing.

Finally, product type was coded as accessories, clothing, lingerie, and shoes. Clothing was defined as selling shirts, pants, panty hose, dresses, skirts, shorts, or a one piece outfit. Lingerie was defined as underwear, braziers, swimsuits, sexy nighttime outfits, strap ups, or any clothing item used for mature activities. Shoes were defined as selling gothic boots, sexy boots, high heels, low heels, tennis shoes, sandals, low tops, high tops, platforms, and wedges. Accessories were defined as selling any other item, such as hair, nails, jewelry, a body enhancement, makeup, wigs, and a complete avatar package. The researcher completed all of the coding. All coded images were downloaded to a computer hard drive for the purpose of coding and intercoder reliability test to ensure consistency.

Prior to coding, a pilot study was conducted to test for intercoder reliability. For the pilot study, 20 percent of the sample (72 still images of female avatar, 24 per category) was coded. Intercoder reliability was conducted by three female coders who had previous exposure to Second Life. All coders were trained to code the data accurately. The researcher described the entire process to the coders, and showed the 
coders the coding book (see appendix A) and coding sheet (see appendix B). Each item in the coding book and coding sheet were explained in detail. In addition, the researcher showed sample still images of full-bodied, female avatars (see appendix D), and explained the differences in each image. After the training process was complete, each coder coded a total of 72 female avatars independently (i.e., $20 \%$ of the sample).

The Cohen's Kappa results indicated that there was a high level of reliability on the coding instrument and among coders. Intercoder reliability was as follows: body size (1.00), product type (.97), coverage (.93), skin color (.93), and beauty type (.71). Solomon, Ashmore, and Longo (1992) suggest that beauty is complex and there will never be complete agreement on distinguishing one beauty type from another. Thus, a minimum of 70 percent intercoder reliability was considered acceptable.

The researcher used Frequency and Explore in SPSS for data screening. Frequency tests were used to answer RQ1 (i.e., What female avatar items were purchased most often for creating an avatar in Second Life?). Chi-square tests were conducted to examine the differences in beauty type to answer RQ2a to RQ2d (i.e., Is there a significant difference in beauty type between avatars with different skin color? with different body size? with different amount of coverage? and among different types of products?). 


\section{CHAPTER IV}

\section{RESULTS}

A total of 360 still images of full-bodied, female avatars in Second Life were coded to examine how beauty is socially constructed in Second Life. Overall, this study found that trendy beauty was the most often used beauty type, followed by sex kitten/sensual, cute/girl next door, and classic. Specifically, 151 avatars (42\%) displayed trendy beauty, $136(38 \%)$ were sex kitten/sensual, 40 (11\%) were cute/girl next door, while 33 avatars (9\%) appeared to be the classic beauty type (see Table 1).

Table 1 Beauty types portrayed in Second Life

\begin{tabular}{lcc}
\hline \multicolumn{1}{c}{ Beauty Type } & Freq. & $\%$ \\
\hline Classic & 33 & $9 \%$ \\
Cute/girl next door & 40 & $11 \%$ \\
Sex kitten/sensual & 136 & $38 \%$ \\
Trendy & 151 & $42 \%$ \\
Total & 360 & $100 \%$
\end{tabular}

In terms of skin color, more than $80 \%$ of the avatars coded in the study (293) had light skin, while only $19 \%$ of the avatars featured dark skin (see Table 2 ). In addition, 
almost all of the female avatars had a perfect body size. This study found that 358 out of the 360 avatars coded in this study had an average (i.e., perfect) body size, while two were overweight, and zero were thin (see Table 3).

Table 2 Skin color used in Second Life

\begin{tabular}{lcc}
\hline \multicolumn{1}{c}{ Skin Color } & Freq. & $\%$ \\
\hline Light Skin & 293 & $81 \%$ \\
Dark Skin & 67 & $19 \%$ \\
Total & 360 & $100 \%$ \\
\hline
\end{tabular}

Table 3 Body size featured in Second Life

\begin{tabular}{lcc}
\hline \multicolumn{1}{c}{ Body Size } & Freq. & $\%$ \\
\hline Average & 358 & $99 \%$ \\
Overweight & 2 & $1 \%$ \\
Thin & 0 & $0 \%$ \\
Total & 360 & $100 \%$ \\
\hline
\end{tabular}

In terms of the body coverage, 139 avatars had little coverage, followed equally by a lot of coverage (i.e., 111 avatars) and moderate coverage (110 avatars, see Table 4). 
Table 4 Body coverage featured in Second Life

\begin{tabular}{lcc}
\hline \multicolumn{1}{c}{ Body Coverage } & Freq. & $\%$ \\
\hline Little Coverage & 139 & $39 \%$ \\
A Lot of Coverage & 111 & $31 \%$ \\
Moderate Coverage & 110 & $30 \%$ \\
Total & 360 & $100 \%$ \\
\hline
\end{tabular}

Research question one is concerned with the types of products purchased most often for creating a female avatar in Second Life. To answer this question, a frequency analysis was conducted. As shown in Table 5, accessories were the most purchased products to create a female avatar in Second Life, followed by clothing, lingerie, and shoes. Overall, 238 images coded in this study were accessories, 95 belonged to clothing, 23 were lingerie, and only four were shoes.

Table 5 Product types purchased in Second Life

\begin{tabular}{lcc}
\hline \multicolumn{1}{c}{ Product Type } & Freq. & $\%$ \\
\hline Accessories & 238 & $66.1 \%$ \\
Clothing & 95 & $26.4 \%$ \\
Lingerie & 23 & $6.4 \%$ \\
Shoes & 4 & $1.1 \%$ \\
Total & 360 & $100 \%$ \\
\hline
\end{tabular}

To answer RQ2a, a Chi-square test was conducted to see if there was a significant difference in beauty type between avatars with different skin color (see Table 6). The 
results indicate that the majority of the avatars with both light skin and dark skin featured the trendy beauty type, followed by sex kitten/sensual, cute/girl next door, and classic. Specifically, among the avatars with light skin, $41 \%$ featured the trendy beauty type, $37 \%$ were sex kitten/sensual, $12 \%$ were cute/girl next door, while only $10 \%$ appeared to be the classic beauty type. Among avatars with dark skin, 48\% were the trendy beauty type, $43 \%$ appeared to be sex kitten/sensual, $8 \%$ were cute/girl next door, and only $1 \%$ featured the classic beauty type. The Chi-square test suggests that there was no significant difference in beauty type between avatars with different skin color $\left(x^{2}=7.60, \mathrm{~d}=3, \mathrm{p}=\right.$ $.055)$.

Table 6 Differences in beauty type between avatars with different skin color

\begin{tabular}{lcccc}
\hline \multirow{2}{*}{ Beauty type } & \multicolumn{2}{c}{ Dark skin } & \multicolumn{2}{c}{ Light skin } \\
\cline { 2 - 5 } & Freq. & $\%$ & Freq. & $\%$ \\
\hline Classic & 1 & $1 \%$ & 32 & $10 \%$ \\
Cute/girl next door & 5 & $8 \%$ & 35 & $12 \%$ \\
Sex kitten/sensual & 29 & $43 \%$ & 107 & $37 \%$ \\
Trendy & 32 & $48 \%$ & 119 & $41 \%$ \\
Total & 67 & $100 \%$ & 293 & $100 \%$ \\
\hline$x^{2}=7.600, \mathrm{~d}=3, \mathrm{p}=.055$ & & & & \\
\hline
\end{tabular}

Research question $2 \mathrm{~b}$ is concerned with the difference in beauty type among avatars with different body size. To answer this research question, a Chi-square test was conducted. The study found that the most often-used beauty type among people with average body size was trendy, followed by sex kitten/sensual, cute/girl next door, and classic. Specifically, $42 \%$ of the avatars with average size appeared to be the trendy 
beauty type, $38 \%$ featured sex kitten/sensual, $11 \%$ were cute/girl next door, and $9 \%$ showed the classic beauty type (see Table 7). Between the two overweight avatars, one showed cute/girl next door, while the other was sex kitten/sensual. The Chi-square test result was not significant $\left(x^{2}=3.85, \mathrm{~d}=3, \mathrm{p}=.279\right)$, which suggests that there was no significant difference in beauty type among avatars with different body size.

Table 7 Differences in beauty type among avatars with different body size

\begin{tabular}{lcccc}
\hline \multicolumn{1}{c}{ Beauty type } & \multicolumn{2}{c}{ Average } & \multicolumn{2}{c}{ Overweight } \\
\cline { 2 - 5 } & Freq. & $\%$ & Freq. & $\%$ \\
\hline Classic & 33 & $9 \%$ & 0 & $0 \%$ \\
Cute/girl next door & 39 & $11 \%$ & 1 & $50 \%$ \\
Sex kitten/sensual & 135 & $38 \%$ & 1 & $50 \%$ \\
Trendy & 151 & $42 \%$ & 0 & $0 \%$ \\
Total & 358 & $100 \%$ & 2 & $100 \%$ \\
$x^{2}=3.85, \mathrm{~d}=3, \mathrm{p}=.279$ & & & &
\end{tabular}

Research question $2 \mathrm{c}$ is concerned with the difference in beauty type among avatars with different amount of body coverage. To answer this research question, a Chisquare test was conducted. Results indicate that the majority of the avatars with a lot of coverage featured the trendy beauty type (54\%), followed by classic (28\%), cute/girl next door (15\%), and sex kitten/sensual (3\%). The majority of the moderate covered avatars were also the trendy beauty type (61\%), followed by sex kitten/sensual (24\%), cute/girl next door (14\%), and classic (2\%). Not surprisingly, the avatars with little amount of body coverage featured the sex kitten/sensual beauty type most frequently $(77 \%)$, followed by trendy (17\%), and cute/girl next door (6\%). None of the 139 avatars with 
little body coverage featured a classic beauty type. The majority of the classic beauty type were covered a lot, the majority of the cute/girl next door beauty type were covered a lot or moderately covered, the sex kitten/sensual beauty type were covered little most of the time, and the trendy beauty type was covered a lot of moderately covered (see Table 8). The Chi-square test result was statistically significant $\left(x^{2}=199.84 \mathrm{~d}=6, \mathrm{p}<.0001\right)$. There was a significant difference in beauty type among avatars with different amount of body coverage.

Table 8 Differences in beauty type among avatars with different body coverage

\begin{tabular}{lcccccc}
\hline \multicolumn{1}{c}{ Beauty Type } & \multicolumn{2}{c}{ A Lot of Coverage } & \multicolumn{2}{c}{ Little Coverage } & \multicolumn{2}{c}{ Moderate Coverage } \\
\cline { 2 - 7 } & Freq. & $\%$ & Freq. & $\%$ & Freq. & $\%$ \\
\hline Classic & 31 & $28 \%$ & 0 & $0 \%$ & 2 & $2 \%$ \\
Cute/girl next door & 17 & $15 \%$ & 8 & $6 \%$ & 15 & $14 \%$ \\
Sex kitten/sensual & 3 & $3 \%$ & 107 & $77 \%$ & 26 & $24 \%$ \\
Trendy & 60 & $54 \%$ & 24 & $17 \%$ & 67 & $61 \%$ \\
Total & 111 & $100 \%$ & 139 & $100 \%$ & 110 & $100 \%$ \\
\hline$x^{2}=199.84, \mathrm{~d}=6, \mathrm{p}<.0001$ & & & & &
\end{tabular}

Research question $2 \mathrm{~d}$ is concerned with the difference in beauty type among different product types. To answer this research question, a Chi-square test was conducted. As seen in Table 9, the majority of the products were purchased for the sex kitten/sensual beauty type, followed by trendy, cute/girl next door, and classic. Among accessories, sex kitten/sensual and trendy were the most frequently used beauty types (44\% and $36 \%$ respectively), followed by cute/girl next door (13\%) and classic (7\%). Among all the clothing items coded, the majority of clothing was purchased for the 
trendy beauty type (65\%), followed by classic (18\%), sex kitten/sensual (9\%), and cute/girl next door (8\%).

Not surprisingly, $91 \%$ of all the lingerie products were shown as sex kitten/sensual. The only other beauty type shown in the lingerie category was cute/girl next door $(9 \%)$. In terms of shoes, $75 \%$ of shoes showed the trendy beauty type, while $25 \%$ showed the sex kitten/sensual beauty type. The Chi-square test was statistically significant $\left(x^{2}=79.68, \mathrm{~d}=9, \mathrm{p}<.0001\right)$. It suggests that there was a significant difference in beauty type among different types of products (see Table 9).

Table 9 Differences in beauty type among different types of products

\begin{tabular}{|c|c|c|c|c|c|c|c|c|}
\hline \multirow[t]{2}{*}{ Beauty type } & \multicolumn{2}{|c|}{ Accessories } & \multicolumn{2}{|c|}{ Clothing } & \multicolumn{2}{|c|}{ Lingerie } & \multicolumn{2}{|c|}{ Shoes } \\
\hline & Freq. & $\%$ & Freq. & $\%$ & Freq. & $\%$ & Freq. & $\%$ \\
\hline Classic & 16 & $7 \%$ & 17 & $18 \%$ & 0 & $0 \%$ & 0 & $0 \%$ \\
\hline $\begin{array}{l}\text { Cute/girl next } \\
\text { door }\end{array}$ & 31 & $13 \%$ & 7 & $8 \%$ & 2 & $9 \%$ & 0 & $0 \%$ \\
\hline $\begin{array}{l}\text { Sex } \\
\text { kitten/sensual }\end{array}$ & 105 & $44 \%$ & 9 & $9 \%$ & 21 & $91 \%$ & 1 & $25 \%$ \\
\hline Trendy & 86 & $36 \%$ & 62 & $65 \%$ & 0 & $0 \%$ & 3 & $75 \%$ \\
\hline Total & 238 & $100 \%$ & 95 & $100 \%$ & 23 & $100 \%$ & 4 & $100 \%$ \\
\hline
\end{tabular}

Overall, in terms of classic beauty, only accessories and clothing products used this beauty type. For cute/girl next door, the majority of the products purchased were accessories and clothing. The sex kitten/sensual beauty type showed accessories most often. In addition, out of the 23 lingerie items coded, 21 showed the sex kitten/sensual beauty type. In terms of trendy beauty, the majority of items featuring this beauty type 
were accessories. Also, $65 \%$ of clothing items and $75 \%$ of shoes showed a trendy beauty type. 


\section{CHAPTER V}

\section{DISCUSSION}

This research examines how beauty is socially constructed in Second Life.

Overall, findings suggest that people chose gender stereotypical even when they have the free choice to create any avatar they desire in Second Life. Trendy and sex kitten/sensual beauty types were the most-portrayed beauty types. Almost all the female avatars had a perfect body size. And more than $80 \%$ of the avatars coded in this study had light skin. In addition, there was a significant difference in beauty type among avatars with different amounts of body coverage and a significant difference in beauty type among different types of products. However, no significant difference was found in beauty type between avatars with different skin color nor was there a significant difference in beauty type among avatars with different body sizes.

Interestingly, this study found that accessories were purchased most often when creating an avatar. Almost $70 \%$ of the products coded in this study were accessories. Since residents can create any avatar they desire, accessories, compared to clothing, lingerie or shoes, can provide users the "ultimate" look that it will be impossible or too costly to achieve in the real life. For example, while a person would have to go through surgery or begin a weight loss program if s/he wanted to have a thinner look, a resident in Second Life can simply purchase a different body size (e.g., thin body shape) with the 
click of a button. Also, in the Second Life Marketplace, the most expensive jewelry item was $\mathrm{L} \$ 2,499$, which is equivalent to a little over $\$ 10.00$ USD. Thus, residents can give their avatars the "luxurious" look when many of them cannot afford it outside of the virtual world.

In addition, this study found no significant difference in beauty types among avatars with different skin color. This could be seen as confirmation that people prefer Ethnocentric features over other physical features. As suggested by previous researchers (e.g., Conrad, Dixon, \& Zhang (2009) and Mbure (2009)), lighter skin models were used more often in advertising and were preferred by the general public. This may explain why $81 \%$ of the coded avatars had light skin. Thus, it illustrates that people still chose the stereotypical skin color that has been used in other advertising outlets, when they had the free choice to choose any in the virtual community. Along the same line, regardless of the options available for creating an avatar in Second Life, all but two avatars coded in this study appeared to have perfect shape. This, ultimately, shows that people rely on and reinforce the stereotype that being the average (i.e., perfect shape) body size is what is considered acceptable.

In Second Life, beauty is socially constructed through the use of symbols (i.e., an avatar). In the game, people choose to create an avatar based on who they look like in real life or what they want to look like (Padilla-Miller, 2009). Essentially, people offer a representation of themselves when they create the avatars. According to Solomon, Ashmore, and Longo (1992), beauty is not a singular notion; there is not a universal meaning for what is considered beautiful. The meaning behind creating an avatar can 
mean different things to people. Essentially, when people create avatars, they choose to manipulate it the way they want.

In Second Life (SL) and the Marketplace, SL users can create any avatar they desire (while they may be limited to the options available to a certain extent). However, this study found Eurocentric features and perfect body shape were still the dominated beauties in Second Life, a virtual community. Findings suggest that the constant exposure to female models in traditional media platform make people become accustomed to the recurring traits of light skin color, a perfect body and other European traits. Overtime, these traits become "reified" within the mind (Berger \& Luckmann, 1966). Thus, when people enter into the virtual world, they enter with the familiar physical traits in mind.

Trendy beauty was the most often portrayed beauty type in Second Life. Trendy beauty type was mainly used for "selling" fashionable clothing, oversized accessories, and dramatic hairstyles in the Second Life Marketplace. A trendy beauty type gives people more freedom to wear outfits that show off certain body parts, or tries certain styles that people have no courage to experiment in real life. These suggest that virtual communities like Second Life do have a potential to deconstruct the stereotypes. Trends in the virtual world can be different from trends in real life.

However, regardless of the individual medium, media perpetuated images constantly reinforce what it means to look like an attractive female. Stereotypes are viewed as "unfair generalizations about groups of people," but they are used on a daily basis (Hermes, 2011, p. 61). In Second Life (SL), anyone around the world can sign up for a SL account and create an avatar. Also, anyone in the world can purchase 
merchandise for their avatars in the Marketplace. Regardless of language spoken, culture, and customs, SL players continue to choose physical features that portray Eurocentric beauty (e.g., light skin color, perfect body size, etc.). Essentially, Hermes (2011) suggests that "the point of stereotyping is to empower media groups, giving them a public voice" (p. 61). When stereotypes occur, it marginalizes the minority population. The power of marginalization allows the media to construct one's reality of stereotypes.

In the real world, people are used to the disappointments that come from the inability to achieve a certain look. It can be done, but it is a huge risk to take. Clothes and accessories are the easiest way to change one's appearance. This may seem simple, but these changes can affect one's self esteem, attitude, and identity. Additionally, it can cause a financial strain on those who do not have the resources to keep up with the current fashion trends (Espinosa Villavicencio, 2007). Changing one's body size or skin color is significantly more difficult to achieve. This can create financial, physical, mental, and emotional stress on a person. Even after enduring procedures to achieve a desired look, a person could still be unsatisfied. Also, a person may not survive if the procedure(s) do not go well (Polonsky, Acar, \& Gregov, 2008).

When people access the virtual world, they seek to create an avatar that is with a perfect shape, fake-looking, and seek any way to enhance the avatar to their satisfaction. Essentially, people want to experience what it is like to look a certain way, even if the experience is virtualized (Hall, 2008). Cooke (2010) says the ability to change one's appearance, with massive possibilities, in a short amount of time showcases that "anything is possible" in the virtual world (p. 396). In Second Life (SL), people can create any avatar they envision or desire, without the costs associated with changing 
one's appearance in real life. In a matter of minutes, a SL user can display sex kitten/sensual beauty type characteristics and change to trendy beauty type characteristics in the next minute. Having this freedom allows users to experiment with and explore beauty type options for a fraction of the cost.

At one time, the real world and the virtual world were separate entities. Today, people question which world is real or if there is only one world (Better Together, 2007). Although the two worlds seem different at a distance, the two worlds have become blurred together. The real world has no distinct definition other than that the world "real" means something exists within the mind (Berger \& Luckmann, 1966, p. 1). Even though Second Life (SL) is a virtual game and exists within a virtual world, the events that take place within the game are synonymous to that of real life. In the past, people have been frustrated with and have tried to fight against unattainable standards presented in real life. However, when they have the chance to create whatever they want, they choose what they fight against in real life.

New media are responsible for the changes and shifts that occur within every dimension of life. Today's media outlets determine the "direction of change from one corner of the world to another" (Singh, 2010, p. 87). New media has become a global culture that connects people all around the world, creating a unified world. Within the unified world, people have adopted certain customs and practices that take place everywhere (Singh, 2010).

In Second Life, users from all over the world join together to create their own economy. Part of the process involves creating an avatar. Given the options presented in 
the game, users strategically created their avatars based on the Western ideals of beauty. Regardless of which beauty type was selected by users, the stereotypes employed in magazines, movies, and other media platforms were employed in the virtual world. Like other media avenues, women are still depicted as sex objects, noted primarily for their looks. Even though people can choose to look anyway they desire, they still reinforce gender stereotypes. Such stereotypes created a skewed view of what Westerners look like and how they behave. However, as long as new media platforms are created and/or enhanced, there will be possibilities for improvement and change. In the meantime, it gives researchers the opportunity to explore virtual phenomenon that would be impossible to explore otherwise. The potential for further exploration increases.

This study was not without limitations. First, although this study provides important insights in understanding the beauty portrayal in Second Life, a content analysis cannot provide in-depth understanding of how and why certain beauty types are selected over other ones. Future studies should institute different methods such as interviews or surveys to provide more accurate and in-depth information and explanation in understanding the social construction of beauty in the virtual community.

In addition, this study analyzed the Marketplace in Second Life. While it is a methodological step in the right direction, the researcher acknowledged the fact that Linden Labs had the control over the standard of beauty. As Biu (2010) suggests, 
gatekeepers have the power to control the world. People who work for the Marketplace ultimately dictate how beauty is perceived in the Marketplace and in Second Life.

Moreover, this study only coded 360 still images of full-bodied, female avatars in the Second Life Marketplace. Future studies could use a larger sample and focus on word choice in addition to still images. Also, the same study could be employed on still images of full-bodied, male avatars. Instead of looking at the different female beauty types, researchers could examine the social construction of male images. Furthermore, price and product reviews may impact the sample of this study. Thus, future research is encouraged to examine the relationship between price and product reviews and people's choices on beauty type in Second Life.

Despite the limitations, this study examines how beauty is socially constructed in Second Life. Ultimately, it suggests that gender stereotypes are perpetuated in the Second Life Marketplace, even though people have the freedom to create any avatar. While great strides have been made to create gender equality, gender stereotypes are being reinforced in Second Life. By examining female avatar construction in the Marketplace, this study yields insights for understanding the social construction of avatar creation and gender norms within the Marketplace and Second Life. Furthermore, it provides understanding, coherence, and value to communication and gender inquiry, and will lead to advance the Theory of Social Construction of Reality in this dynamic new media environment. 


\section{REFERENCES}

Ananthaswamy, A. (2007). A life less ordinary offers far more than just escapism. New Scientist, 195(2618), 26-27.

Armstrong, E. \& Ferguson, A. (2010). Language, meaning, context, and functional communication. Aphasiology, 24(4), 480-496.

Atkinson, T. (2008a). Inside linden lab. Tech Trends: Linking Research \& Practice to Improve Learning, 52(2), 18-21.

Atkinson, T. (2008b). Myths and realities. Tech Trends: Linking Research \& Practice to Improve Learning, 52(5), 26-29.

Ayiter, E. (2010). Embodied in a metaverse: 'Anatomia' and 'body parts'. Technoetic Arts: A Journal of Speculative Research, 8(2), 181-188.

Bandura, A. (2001). Social cognitive theory of mass communication. Media Psychology, 3, 265-299.

Barker, R. (2008). Presentation of the virtual beyond-self on cyber stage: Real, constructed, staged, and/or masked? Communication: South African Journal for Communication Theory \& research, 34(2), 189-209.

Behm-Morawitz, E. \& Mastro, D.E. (2008). Mean girls? The influence of gender portrayals in teen movies on emerging adults' gender-based attitudes and beliefs. Journal \& Mass Communication Quarterly, 85(1), 131-146.

Bélisle, J.F. \& Bodur, H.O. (2010). Avatars as information: Perception of consumers based on their avatars in virtual worlds. Psychology \& Marketing, 27(8), 741-765.

Benoy, J.W. (1982). The credibility of physically attractive communicators: A review. Journal of Advertising, 11(3), 15-25.

Berger. P.L. \& Luckmann, T. (1966). The social construction of reality. Garden City, NY: Doubleday.

Better together. (2007). Economist, 385(8558), 14-14. 
Biu, C. (2010). How online gatekeepers guard our view-News portals' inclusions and ranking of media and events. Global Media Journal: American Edition, 9(16), $1-41$.

Bordo, S. (1993). Unbearable weight: Feminism, western culture, and the body. Berkeley: University of California.

Brabant, S. (2010). Death: The ultimate social construction of reality. Omega: Journal of Death \& Dying. 62(3), 221-242.

Brennen, B. \& dela Cerna, E. (2010). Journalism in second life. Journalism studies, 11(4), 546-554.

Brookey, R.A. \& Cannon, K.L. (2009). Sex lives in second life. Critical Studies in Media Communication, 26(2), 145-164.

Bullen, R.R. (2009). The power and impact of gender-specific media literacy. Youth Media Reporter, 3, 149-152.

Chu, S., Paul, N., \& Ruel, L. (2009). Using eye track technology to examine the effectiveness of design elements on news websites. Design Journal, 17(1), 31-43.

Conrad, K., Dixon, T., \& Zhang, Y. (2009). Controversial rap themes, gender portrayals and skin tone distortion: A content analysis of rap music videos. Journal of Broadcasting \& Electronic Media, 53(1), 134-156.

Cooke, G. (2010). De-inter-facement. Convergence: The International Journal of Research into New Media Technologies, 16(4), 395-410.

Covergirl \& olay tone rehb 2-in-lfoundation. (2012). Retrieved from http://www/cover girl.com/tonerehab

Damme, E.V. (2010). Gender and sexual scripts in popular US teen series: A study on the gendered discourses in one tree hill and gossip girl. Catalan Journal of Communication \& Cultural Studies, 2(1), 77-92.

Diehl, W.C. \& Prins, E. (2008). Unintended outcomes in second life: Intercultural literacy and cultural identity in a virtual world. Language \& Intercultural Communication, 8(2), 101-118.

Dream nude airfoam. (2012). Retrieved from http://www.maybelline.com/ products/156/face/foundation/dream-nude-airfoam/classicivory $/ 150$ ? shadeId $=856$ 
Ellis, K. (2010). Be who you want to be: The philosophy of Facebook and the construction of identity. Screen Education, (58), 36-41.

Emons, P., Wester, F., \& Scheepers, P. (2010). "He works outside the home; She drinks the coffee and does the dishes." Gender roles in fiction programs on Dutch television. Journal of Broadcasting \& Electronic Media, 54(1), 40-53.

Englis, B.G., Solomon, M.R., \& Ashmore, R.D. (1994). Beauty before the eyes of the beholder: The cultural encoding of beauty types in magazine advertising and music television. Journal of Advertising, 23(2), 49-64.

Espinosa Villavicencio, J., 2007. Fashion houses and brands: Projecting their identity and establishing a two-way communication online in an old-fashion way. Paper presented at the International Communication Association, (pp. 1-33).

Gillath, O., McCall, C., Shaver, P.R., \& Blascovich, J. (2008). What can virtual reality teach us about prosocial tendencies in real and virtual environments? Media Psychology, 11(2), 259-282.

Goodman, J.R., Morris, J.D., \& Sutherland, J.C. (2008). Is beauty a joy forever? Young women's emotional responses to varying types of beautiful advertising models. Journalism \& Mass Communication Quarterly, 85(1), 147-168.

Hall, G.P. (2008). Choosing life or second life? Discipline and agency in a mediated culture. International Review of Mission, 97(384/385), 7-20.

Harambam, J., Aupers, S., \& Houtman, D. (2011). Game over? Negotiating modern capitalism in virtual game worlds. European Journal of Cultural Studies, 14(3), 299-319.

Harcourt, W. (2011). Using the master's tools: Women's movements and social media. Media Development, 58(1), 19-22.

Harrison, J. (2009). A virtual society. Rocky Mountain Communication Review, 6(1), 5-7.

Hermes, J. (2011). On stereotypes, media, and redressing gendered social inequality. Annals of Spiru Haret University, Journalism Studies, 12(1), 61-63.

Hirsch, R. (2010). Language as reflective experience. Semiotica, 182(1-4), 215-228.

Huang, J.S. (2011). An examination of the business strategies in the second life virtual market. Journal of Media Business Studies, 8(2), 1-17. 
Ibroscheva, E. \& Ramaprasad, J. (2007). A social construction model of stereotypes of foreigners. Paper presented at the National Communication Association, (pp. 1-31).

Ibroscheva, E. \& Ramaprasad, J. (2008). Do media matter? Journal of International Communication, 16, 1.

Ilbuga, E.U. (2010). Representations of foreign women in the Turkish media: A study done on regional supplements of national newspapers and local newspapers in Antalya. Ileti-sim,(13), 29-53.

Inceoglu, Y. \& Kar, A. (2009). New beauty icons: Freedom or conviction to the human body. Ileti-s-im,(10), 7-31.

Internet users \& population statistics for the Americas. (2011). Retrieved from http://www.internetworldstats.com/stats2.htm

Jin, S.A. (2010). "I feel more connected to the physically ideal mini me than the mirrorimage mini me": Theoretical implications of the "malleable self" for speculations on the effects of avatar creation on avatar-self connection in Wii. Cyber Psychology, Behavioral \& Social Networking, 13(5), 567-570.

Joseph, W.B. (1982). The credibility of physically attractive communicators: A review. Journal of Advertising, 11(3), 15-24.

Kaplan, A.M. \& Haenlein, M. (2009). Consumer use and business potential of virtual worlds: The case of "Second Life." The International Journal on Media Management, 11, 93-101.

Kaufman, D. (2000). Descartes on the objective reality of materially false ideas. Pacific Philosophical Quarterly, 81(4), 385-408.

Law, C. \& Labre, M.P. (2002). Cultural standards of attractiveness: A thirty-year look at changes in male images in magazines. Journalism \& Mass Communication Quarterly, 79(3), 697-711.

Lee, J.E.R. \& Park, S.G. (2009). Identity threat versus safety for racial minorities in virtual worlds: Effects of numerical representation of race as a diversity cue. Paper presented at the International Communication Association, (pp. 1-30).

Lin, C.L. \& Yeh, J.T. (2009). Comparing society's awareness of women: Mediaportrayed idealized images and physical attractiveness. Journal of Business Ethics, 90(1), 61-79. 
Lin, H.F. (2009). Examination of cognitive absorption influencing the intention to use a virtual community. Behaviour \& Information Technology, 28(5), 421-431.

Lipschultz, J.H. \& Hilt, M.L. (1999). Mass media and the death penalty: Social construction of three Nebraska executions. Journal of Broadcasting \& Electronic Media, 43(2), 1-18.

Luckmann, T. (1989). On meaning in everyday life and in sociology. Current Sociology, $37(1), 17-30$.

Luckmann, T. (1967). The invisible religion. NY: The Macmillan Company.

Mbure, W. (2009). Beauty through the eyes of cosmetics: The construction of beautiful faces through cosmetic advertising in black magazines. Paper presented at the International Communication Association (pp. 1-23).

Mcquail, D. (2010). Mcquail's mass communication theory $\left(6^{\text {th }}\right.$ ed). London: Sage.

Menegatos, L. (2007). Using religious discourse to construct reality: How George W. Bush and Osama bin Laden united and divided nations. Paper presented at the National Communication Association, (pp. 1-29).

Morris, P. (2006). Gender in print advertisements: A snapshot of representations from around the world. Paper presented at the International Communication Association (pp. 1-29).

Neuendorf, K., Gore, T., Janstova, P., \& Snyer-Suhy, S. (2007). "Bond girls," shaken and stirred: A content analysis of James Bond films. Paper presented at the National Communication Association (pp. 1-35).

O’Brien, M.G. \& Levy, R.M. (2008). Exploration through virtual reality: Encounters with the target culture. Canadian Modern language Review, 64(4), 663-691.

Padilla-Miller, A. (2009). Body image in second life: Improving physical insecurities or Perpetuating them? Proceeds of the Annual Meeting of the International Communication Association (pp. 1-24).

Patzer, G. L. (1985). The physical attractiveness phenomena. New York: Plenum Press.

Pitura, A. (2010). Idealism: Factors affecting the body image of college students. Journal of the Communication, Speech \& Theatre Association of North Dakota, 23, 62-68.

Polonsky, M., Acar, S. \& Gregov, J. (2008). “Cut me a break!” Effects of media and social pressure on behavioral intentions to get cosmetic surgery. Paper presented at the International Communication Association, (pp. 1-29). 
Raine, L. (2010, January 5). Internet, broadband, and cell phone statistics. Retrieved from http://www.pewinternet.org/Reports/2010/Internet-broadband-and-cellphone $\%$ statistics.aspx

Rak, J. (2009). The electric self: Doing virtual research for real in second life. Biography: An Interdisciplinary Quarterly, 32(1), 148-160.

Rask. A. (2007). Video game vixens: Shaping men's perception of beauty? Paper presented at the International Communication Association (pp. 21).

Robinson, T., Callister, M., Clark, B., \& Phillips, J. (2009). Violence, sexuality, and gender stereotyping: A content analysis of official video game websites. Web Journal of Mass Communication Research, 13, 1-17.

Rodkin, P.C. (1993). The psychological reality of social constructions. Ethnic \& Racial Studies, 16(4), 633-657.

Second life marketplace. (2012). Retrieved from https://marketplace.secondlife.com/

Signorielli, N. \& McLeod, D. (1994). Gender stereotypes in mtv commercials: The beat goes on. Journal of Broadcasting \& Electronic Media, 38(1), 91-112.

Simpson, B. (2011). What happens online stays online? Virtual punishment in the real world. Information \& Communications Technology Law, 20(1), 3-17.

Singh, C.L. (2010). New media and cultural identity. Chinese Media Research, 6(1), 86-90.

Siu, W. (2006). Social construction of reality: Media framing of tobacco issues. Paper presented at the International Communication Association, (pp. 1-46).

Smith, C. (2010). Internet usage statistics: How we spend our time online. Retrieved From http://www.huffingtonpost.com/2010/06/22/internet-usage-statistics n_ 620946.html

Solomon, M.R., Ashmore, R., \& Longo, L.C. (1992). The beauty match-up hypothesis: Congruence between types of beauty and product images in advertising. Journal of Advertising, 21(4), 23-34.

Storr, V. (2010). The social construction of the market. Society, 47(3), 200-206.

True match super blend makeup. (2012). Retrieved from http://www.lorealparisusa. Com/_us_en/default.aspx 
VoCiC, Z. (2008). Media, identity, and gender: Tracking feminist media and journalism theories and methodologies. Medijska Istrazivanja/Media Research, 14(1), 5-21.

Wainwright, D., Nagler, R., \& Serazio, M. (2007). Buy me, be me: Gender, sexuality, and thin-ideal messages in teen magazine advertisements. Paper presented at the National Communication Association, (pp. 1-27).

Wrench, J.S., Thomas-Maddox, C., Richmond, V.P., \& McCroskey, J.C. (2008). Quantitative research methods for communication. Oxford, NY: Oxford University Press, Inc.

$\mathrm{Wu}, \mathrm{H}$. (2006). The construction of consumer population: A gender analysis of advertising in the 1920s China. Paper presented at the International Communication Association, (pp. 1-51).

Zhao, S. (2006). The internet and the transformation of the reality of everyday life:

Toward a new analytic stance in sociology. Sociological Inquiry, 76(4), 458-474.

Zheng, D., Young, M.F., Wagner, M.M., \& Brewer, R.A. (2009). Negotiation for action: English language in game-based virtual worlds. Modern Language Journal, 93(4), 489-511. 
APPENDICES 
APPENDIX A

CODING SHEET

Case number:

\section{Category: \\ $1=$ Avatar accessories: \\ 2 = Avatar apparel: \\ $3=$ Avatar appearance:}

\section{Beauty type:}

$1=$ Classic:

$2=$ Cute/Girl next door:

3= Sex kitten/Sensual:

4= Trendy:

3. Skin color:

$1=$ Dark:

2 = Light: 
4. Body size:

$1=$ Average:

$2=$ Overweight:

3 = Thin:

5. Coverage:

$1=$ A lot of coverage:

$2=$ Moderate coverage:

3 = Little coverage:

\section{Product:}

$1=$ Accessories:

$2=$ Clothing:

$3=$ Lingerie:

4 = Shoes: 


\section{APPENDIX B}

\section{CODING BOOK}

Categories: Avatar accessories: Choose avatar accessories from the "search in" dropdown menu

Avatar apparel: Choose apparel from the "search in" dropdown menu

Avatar appearance: Choose avatar appearance from the "search in" dropdown menu

Beauty type: Classic: A classic and elegant look. Fair skin, feminine, glamorous and sophisticated. These avatars look perfect, have symmetrical physical features, have a soft, romantic look, and wear classy, formal attire.

Girl next door/Cute: Cute, casual attire, youthful physical features. They can be outdoorsy, in a casual, active way. These avatars can look like fresh-faced teenagers. They may be seen holding a stuffed animal, wearing pig tails, wearing teenager pajamas, and wearing animal accessories (tail, ears, etc.) in a childish way (NOT in a sexual way).

Sex-kitten/Sensual: Sexually attractive, usually wears sexy attire or revealing, tight clothes. Avatar can also be dressed in normal clothes but posed in an unnatural way, such as uncomfortable, "cheesecake" pose (chest thrust forward, back arched). These avatars may look to please a sexual partner.

Trendy: Wears faddish clothes and displays oversized accessories. Hair is tousled; there is a slight sense of chaos to this type, (offbeat look). Can also have an "I don't give a damn" attitude. These avatars are asymmetrical or flawed in comparison to the Classic beauty type. These avatars sometimes wear skimpy outfits, but they may look like a costume, an outfit to celebrate a holiday or culture custom, or worn with wings.

Skin color: Dark skin: Tan, honey, tawny, dark brown, cocoa, darkened

Light skin: Ivory, pale white, nude, light khaki 
Body size: Average: Has a little bit of fat; looks healthy; has curves that are proportionate to the body.

Overweight: Looks overweight; excess body fat, displays rolls, enlarged thighs, and has a gut.

Thin: Looks too thin, possibly looks anorexic; has no curves

Coverage: $\quad$ A lot of coverage: Shows less than one half to no total body skin; looks conservative; no inappropriate body parts exposed.

Moderate coverage: Half of the total body skin is exposed; these avatars may have a bra on and wear pants at the same time and it doesn't look like she's about to be naked; some cleavage may be present, but covered for the most part; wear shorts and a tank top that are short, but still cover those parts without them falling out

Little coverage: More than half of total body skin is exposed; wears skimpy lingerie or skimpy outfit; private parts are practically popping out of the clothes; wears a little dress where the boobs are popping out and doesn't cover the private area too well; may wear a shirt and pants, but look like she's ready to fall out of her clothes.

Product: $\quad$ Accessories: Hair (Hair style, hair color, hair textures, hair weave, hair extensions, feathers, hair dye), nails (color, designs, length), Jewelry (Finger ring, toe ring, necklace, bangles, earrings, bracelets, belly chain), and anything else that can be added to the body for enhancement purposes, body enhancement (breast pads, fake breasts, lip enhancement, curvy body, toned body, color skin (light, medium, dark), Makeup (eye shadow, lip stick, lip gloss, blush, eye liner, mascara, foundation)), wings, complete avatar package, and any other item that is not clothing, lingerie, or shoes

Clothing: Shirt, pants, panty hose, dress, skirt, shorts, one piece outfit

Lingerie: Underwear, brazier, swimsuit, sexy nighttime outfit, strap ups, and any clothing used for mature activities

Shoes: Gothic boots, sexy boots, high heels, low heels, tennis shoes, sandals, low tops, high tops, platforms, wedges 
APPENDIX C

EXAMPLE PHOTOGRAPHS

Examples of beauty types

Classic

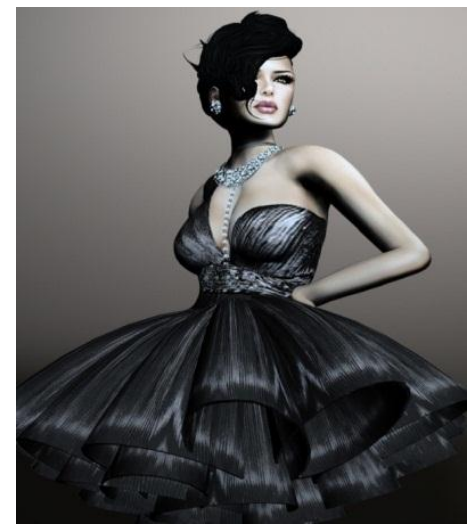

Sex kitten/sensual

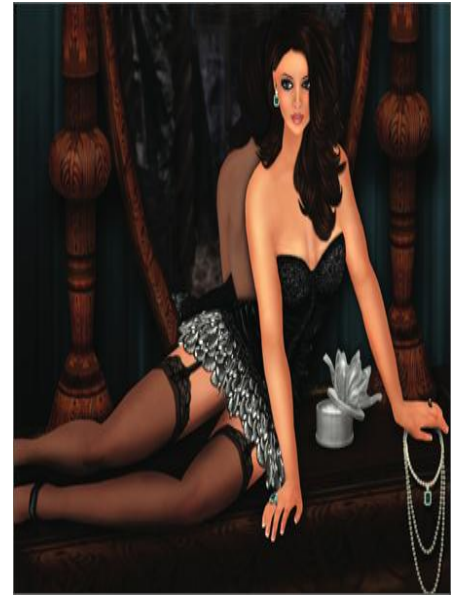

Cute/girl next door

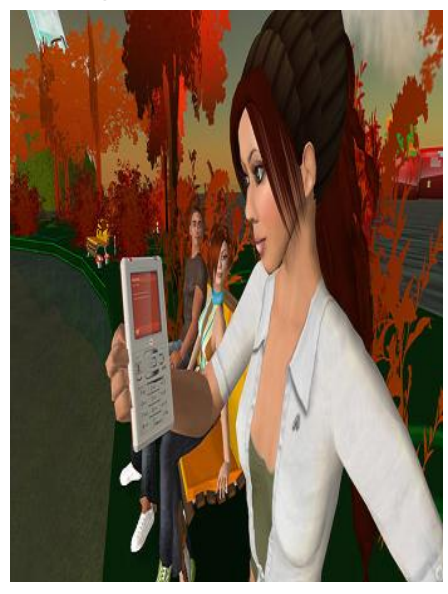

Trendy

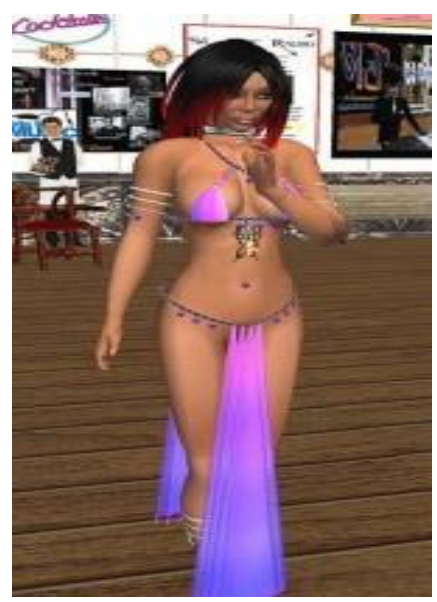




\section{Examples of skin color}

Dark skin

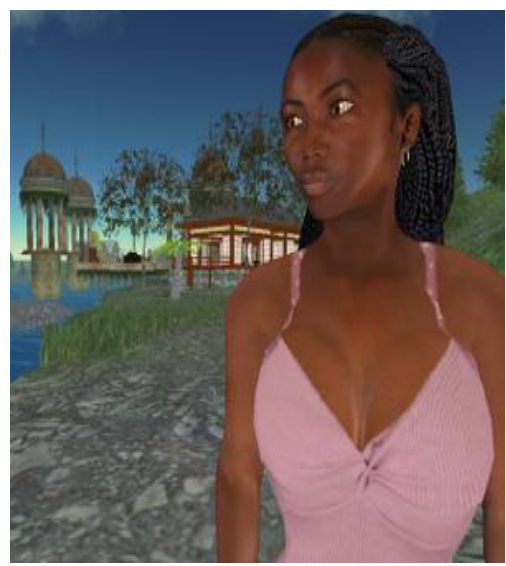

Examples of body size

Average

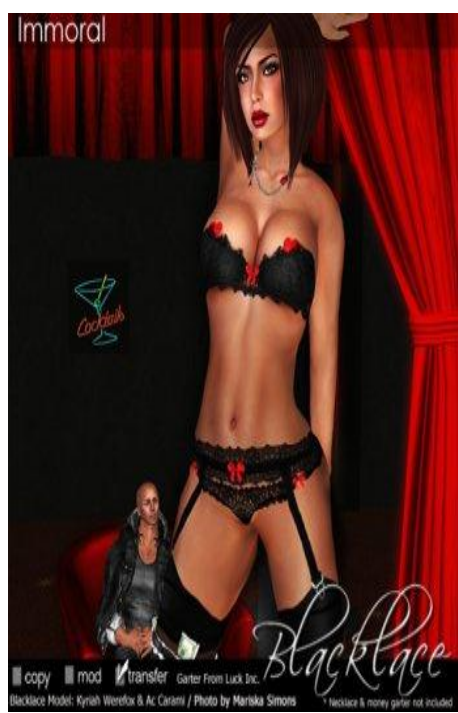

Light skin

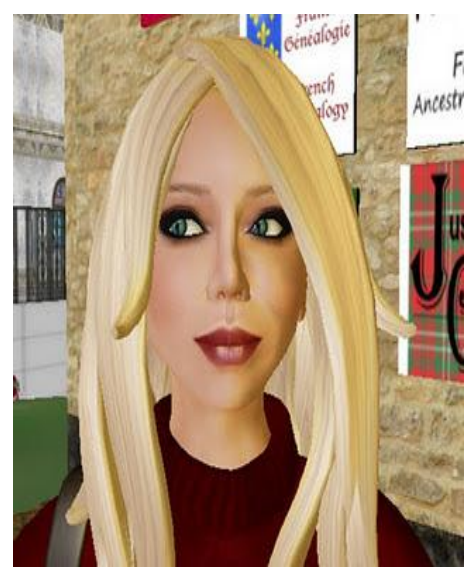

Overweight

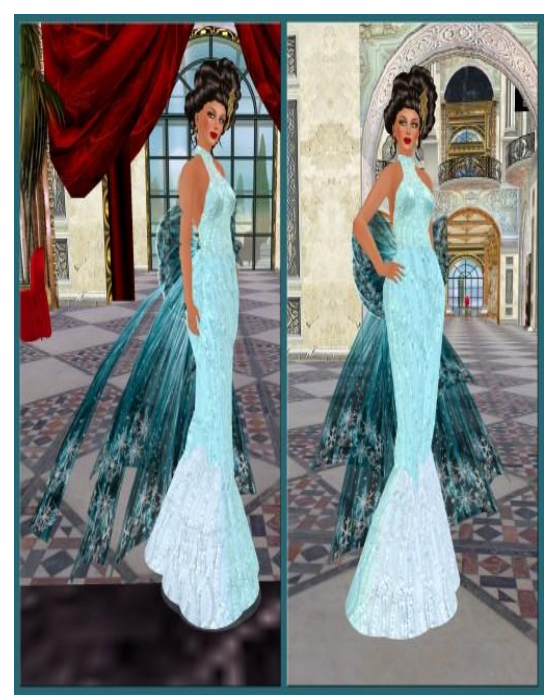


Thin

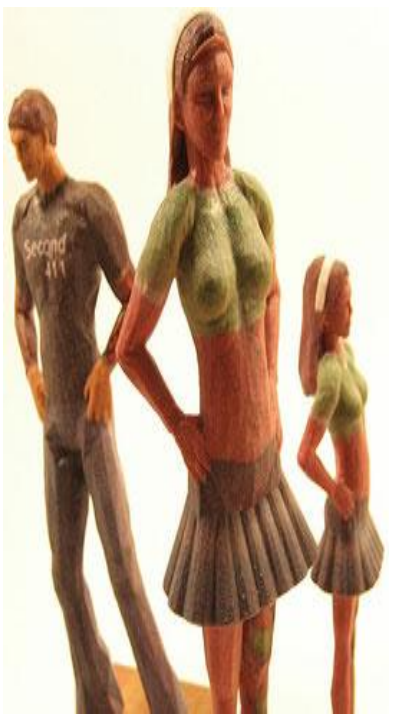

Examples of coverage

A lot of coverage

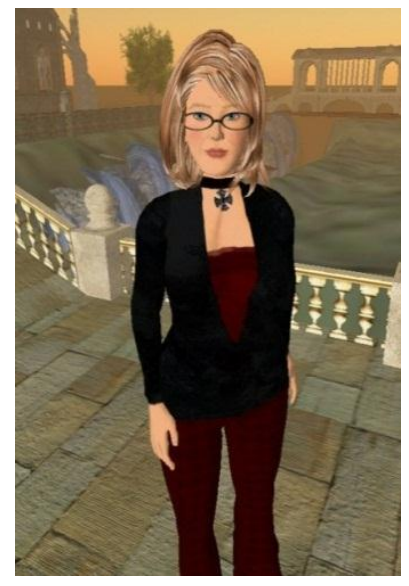

Moderate coverage

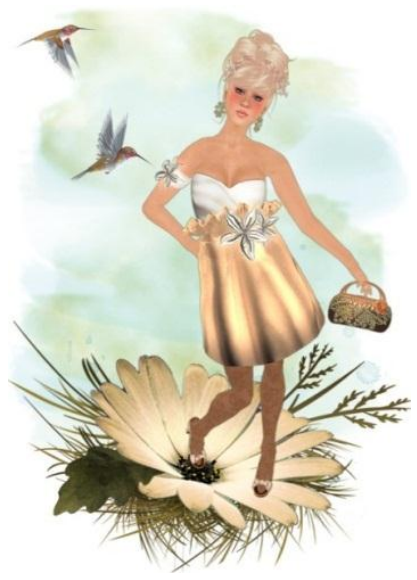


Little coverage

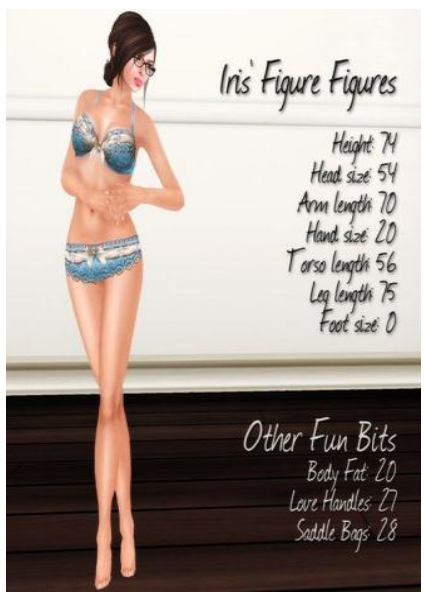

